taken as representative of at least the consultant part of the profession. The proliferation of colleges has also led to the emergence of the Conference of Medical Royal Colleges and their Faculties in the UK. This is purely a consultative body, but it is a valuable forum for the exchange of ideas. It is yet another sign of the necessity for the professions in the late twentieth century to be more self-conscious and aware of their changing roles. Nevertheless, as Lord Smith and Professor Linford Rees have both said recently, the Royal Colleges have always existed for the care of patients, and we should never forget that this remains our fundamental purpose.

Being in existence for seven years seems as good a time as any for a reappraisal of past achievements and possible future tasks. I have therefore suggested that we should have a two-day meeting of members of Council (not a Council meeting-there will be no minutes) so that we can talk at length, free from the demands of a formal agenda, on possible changes in College functions and structure. Topics will be chosen after consultation, and Divisions and Sections are all being asked for their suggestions. So far, possible topics include; the teaching of psychiatry to general practitioner trainees; psychiatry in general hospitals; relationships with non-medically qualified colleagues, especially psychotherapists in the light of impending legislation; manpower problems; the continuing education of consultants and problems of "medical audit"; and the internal organization of the College with special reference to meetings, committees, etc. If any member of the College is seized with some particularly important matter and would prefer to write to me directly about it rather than go through his Division or Section, I shall be happy to hear from him or her.

Desmond Pond

\title{
APPROVAL REPORTS
}

The following letter has been sent to Clinical Tutors in Psychiatry and Chairmen of Senior Registrar Committees (or others in charge of higher training programmes in Psychiatry) and is reproduced here for information.

\section{Dear Sir/Madam,}

The Royal College of Psychiatrists is responsible for inspecting hospitals to decide if they are suitable for general professional training in Psychiatry, which means that they are concerned with trainees, generally in the Registrar and SHO grades, who are working for the M.R.C.Psych. examination.

The Joint Committee on Higher Psychiatric Training (which consists of six representatives of the Association of University Teachers of Psychiatry, six representatives of the Royal College of Psychiatrists, and the President and Dean of the College) is the body concerned with higher professional training. This means that in general they are concerned with inspecting Senior Registrar posts, both in general psychiatry and the specialties of psychiatry.

The College's programme of approval visits to review general professional training in psychiatry commenced before that of the Joint Committee, and in order to obviate unnecessary duplication it has been customary to ask a hospital that has been visited by the College if there would be any objection to the College's report being made available to the convenor of the J.C.H.P.T.'s visiting panel, and this has always been agreed. It would seem desirable in future, when a hospital has been visited by the Joint Committee, that the convenor of a College visiting panel should similarly have a copy of the J.C.H.P.T.'s report when a further visit is made.

In order to simplify the procedure, rather than writing individually to every hospital before each visit to enquire if a report may be made available, we are writing jointly to all hospitals to suggest that it would be sensible to make these arrangements routinely. This we propose to do in future, unless any hospital replies to this letter specifically requesting that it would wish to have such a report withheld from a convenor.

Yours faithfully,

D. A. Pond

President, Royal College of Psychiatrists

H. J. Walton

Chairman, Joint Committee on Higher Psychiatric Training 